\title{
Erratum: The output employment elasticity and the increased use of temporary contracts: Evidence from Poland
}

\author{
KRISTOF BARTOSIK ${ }^{1 *}$ and JAN MYCIELSKI ${ }^{2}$ \\ ${ }^{1}$ Institute of Economics of the Polish Academy of Sciences, Nowy Swiat 72, 00-001, Warsaw, Poland \\ ${ }^{2}$ Faculty of Economic Sciences, University of Warsaw, Warsaw, Poland
}

Received: July 21, 2020

(๔ 2020 Akadémiai Kiadó, Budapest

ERRATUM: Acta Oeconomica 70 (2020) 1, 83-104

DOI: $10.1556 / 032.2020 .00005$

The authors' names were published incorrectly. The correct form of the authors is as follows: KRZYSZTOF BARTOSIK JERZY MYCIELSKI

*Corresponding author. E-mail: kbartosik0303@gmail.com 